\title{
COPE-ICD: A randomised clinical trial studying the effects and meaning of a comprehensive rehabilitation programme for ICD recipients -design, intervention and population
}

Selina K Berg ${ }^{1,2^{*}}$, Jesper H Svendsen ${ }^{1,3,4}$, Ann-Dorthe Zwisler ${ }^{1,5}$, Birthe D Pedersen ${ }^{6}$, Pernille Preisler ${ }^{1}$, Lone Siersbæk-Hansen ${ }^{1}$, Mette B Hansen ${ }^{1}$, Rune H Nielsen ${ }^{1}$ and Preben U Pedersen ${ }^{2}$

\begin{abstract}
Background: Growing evidence exists that living with an ICD can lead to fear and avoidance behaviour including the avoidance of physical activity. It has been suggested that psychological stress can increase the risk of shock and predict death. Small studies have indicated a beneficial effect arising from exercise training and psychological intervention, therefore a large-scale rehabilitation programme was set up.

Methods/Design: A mixed methods embedded experimental design was chosen to include both quantitative and qualitative measures. A randomised clinical trial is its primary component. 196 patients (power-calculated) were block randomised to either a control group or intervention group at a single centre. The intervention consists of a 1 -year psycho-educational component provided by two nurses and a 12-week exercise training component provided by two physiotherapists. Our hypothesis is that the COPE-ICD programme will reduce avoidance behaviour, sexual dysfunction and increase quality of life, increase physical capability, reduce the number of treatment-demanding arrhythmias, reduce mortality and acute re-hospitalisation, reduce sickness leading to absence from work and be cost-effective. A blinded investigator will perform all physical tests and data collection.

Discussion: Most participants are men (79\%) with a mean age of 58 (range 20-85). Most ICD implantations are on primary prophylactic indication (66\%). $44 \%$ is NYHA II. Mean walk capacity (6MWT) is $417 \mathrm{~m}$. Mean perception of General Health (SF-36) is PCS 42.6 and MCS 47.1.

A large-scale ICD rehabilitation trial including psycho-educational intervention and exercise training has been initiated and will report findings starting in 2011.
\end{abstract}

Trial Registration: ClinicalTrials.gov: NCT00569478

\section{Background}

Treatment with Implanted Cardioverter Defibrillators (ICD) has reduced mortality remarkably during the past 20 years. It has resulted in new, more extensive guidelines for the implantation of ICDs [1]. The average ICD implantation rate in Europe is 140 per million inhabitants (in Denmark 180 per million) and in the USA the rate is considerably higher, 416 per million

\footnotetext{
* Correspondence: selina@rh.dk

'Rigshospitalet, The Heart Center, University of Copenhagen, Copenhagen, Denmark

Full list of author information is available at the end of the article
}

[2]. Studies have shown that living with an ICD can lead to anxiety, fear of shock and avoidance of situations, places and objects that the patients associate with shock. It often leads to social isolation, avoidance of physical activity, including sexual activity and mood disturbances [3-8]. In addition, it has been suggested that negative emotions could be the cause rather than the result of arrhythmia, and that psychological stress can increase the risk of shock [9-11]. Furthermore, psychosocial status seems to predict mortality [12]. It is unclear if cardiac rehabilitation can reduce the risk of shock or death.

\section{Biomed Central}

(c) 2011 Berg et al; licensee BioMed Central Ltd. This is an Open Access article distributed under the terms of the Creative Commons Attribution License (http://creativecommons.org/licenses/by/2.0), which permits unrestricted use, distribution, and reproduction in any medium, provided the original work is properly cited. 
During the past 10 years several, often small, interventional studies have been carried out aiming to improve every day functioning of patients with ICD.

\section{Exercise training}

Patients enrolled in out-patient rehabilitation (OCR) tend to exercise more often, 4 times a week versus - 3 times a week in the case of non-OCR patients, and with a higher intensity 5.3 METS (metabolic equivalent) versus 3.5 METS in non-OCR patients [13]. Exercise training in a rehabilitation format has been shown to be safe [14-17], to improve cardiopulmonary fitness e.g. exercise time [14], METS [18], Peak Vo2 [14-17] and reduce anxiety [14] and improve quality of life [15].

\section{Psycho-intervention}

Psychological [19]/psycho educational [20-22]/cognitive behavioural $[11,23,24]$ interventions have either a group format [24] or an individual format $[19,20]$ with face to face consultations [24] or telephone counselling $[11,19,24]$. Psychological intervention seems to have a beneficial effect on anxiety and perceived physical health in patients younger than 65 years but may lead to symptom increase in older patients [19]. Psycho-educational intervention seems to reduce anxiety $[20,21,25]$ and enhance knowledge [20]. However in the computer based format there were no beneficial effects [22]. Cognitive behavioural rehabilitation has shown to improve physical health, reduce anxiety $[11,23]$ and depression, and lower unplanned admissions [23]. However in a group format no difference in quality of life was found [24].

\section{Combined interventions}

A few randomized trials have combined exercise training and cognitive behavioural intervention. In a study by Frizelle et al. from 2004, 22 patients were included, half in an intervention group and half in a waiting group, beginning rehabilitation after 3 months. The intervention consisted of a weekly two-hour group meeting over a 6 week period and a follow up telephone call at 9 weeks. Significant improvements in anxiety, depression, quality of life and physical capacity were observed [26]. Similarly Fitchet et al. compared 16 patients randomised either to a 12 week (twice weekly) rehabilitation programme or a waiting group, beginning rehabilitation after 3 months. The intervention consisted of exercise training and psycho-educational intervention in a group format. This resulted in improved exercise time, and reduced anxiety and depression [27].There have been calls for a well-powered study combining psycho-educational intervention and exercise training [21]. We have now developed and completed enrolment for just such a study. The purpose of the COPE-ICD trial, to our knowledge, the largest randomised clinical intervention trial studying ICD rehabilitation, is to describe the effect and meaning of an outpatient programme including psycho-educational consultations and exercise training for patients with ICD. This paper summarises the study design and the baseline characteristics of the participants.

\section{Hypothesis}

Our hypothesis is that the COPE-ICD programme will:

- reduce avoidance behaviour and increase quality of life

- reduce fear of exercise and increase physical capability.

- reduce sexual dysfunction

- reduce the number of treatment-demanding arrhythmias and ICD shocks.

- reduce mortality

- reduce acute re-hospitalization

- reduce sickness absence and improve employment status in the long term

- be cost effective

\section{Methods/Design \\ Trial design}

The COPE-ICD trial combines quantitative and qualitative research methods. The methods are integrated by applying a mixed methods embedded experimental design (Figure 1) [28]. The quantitative method utilises the traditional randomised controlled trial (RCT). The qualitative methods utilises extensive interviews of a small selected subset of intervention patients. The qualitative data will help explain the quantitative findings. The rationale for this approach is that the quantitative data and their subsequent analysis provide a general understanding of the research problem. The qualitative data and their analysis refine and explain the statistical results by exploring participants' views in more depth.

\section{Participants}

The setting is a large university hospital with a volume of approximately 300 first time ICD implantations every year.

\section{Eligibility}

Inclusion - Patients who received an ICD for the first time, and who prior to hospital discharge agreed to participate in the entire programme.

- Patients with physician permission prior to randomization to participate in the physical training programme.

Exclusion - Patients who do not understand the study instructions. 


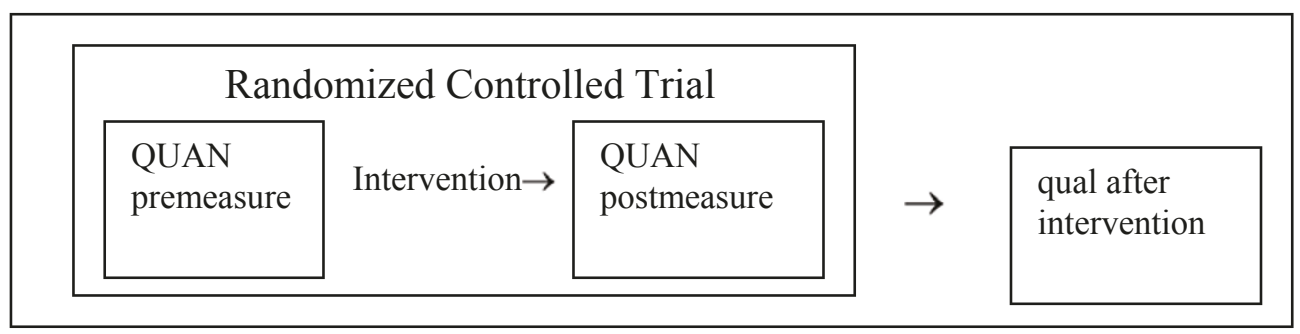

$$
\begin{aligned}
& \text { QUAN= Qantitative measures (primary outcome mesures) } \\
& \text { qual= Qualitative measures (secundary supportive measures) }
\end{aligned}
$$

- Patients who are under 18 years of age.

- Patients who are diagnosed with a psychiatric disease.

- Patients with other somatic diseases, where recovery might influence the study.

\section{Randomisation}

Before randomisation baseline data were collected. Patients were randomised while in hospital.

The enrolling research assistant or primary investigator called for randomization allocation. Randomisation (block of 4) was done by voice-respondent in a 1:1 ratio to intervention group or control group (standard care) and there was stratification according to gender and left ventricular ejection fraction (below or above 35\%).

\section{Intervention COPE-ICD}

\section{Psycho-educational intervention}

The programme is based on a humanistic approach, focusing on psychosocial support and education. The programme is directed towards the parameters that ICDs reportedly affect. The content is made up of information and education focused on managing life with an ICD, including emotional reactions (Table 1) using a holistic view on the person and establishment of a joint approach to disease management and coping. Nursing care is inspired by R.R Parse's Human Becoming Practice Methodologies 3 dimensions [29] that are interpreted as: 1, discuss and give meaning to the past, present and future 2, explore and discuss events and possibilities and 3, move along with envisioned possibilities. According to this theory there are 3 ways of changing health: creative imaging that is see, hear and feel what a situation might be like if lived in a different way, affirming personal patterns and value priorities, and shedding light on paradoxes, that is looking at the incongruence in a situation and changing the view held of something. The nurse is true present in the process through discussions, silent immersion and reflection. The consultations take place in a quiet setting at the out-patient clinic. The nurse is able to facilitate contact to or seek advice with a physician or a technician.

The patients consult the nurse in person or by phone once a month for 6 months, and every 2 months thereafter, for the following 6 months. The frequency is based on clinical experience where transportation to the hospital and the need for psycho-educational support are considered. Relatives are invited to participate once or twice if needed. The psycho-educational part of the intervention is performed by two nurses with 10 years of clinical experience each in the care for patients with ICDs. The nurses do not care for ICD patients at the in-hospital unit during the project period to prevent "contamination" of the control group.

\section{Exercise training program}

Three months after the ICD implantation, training is done twice a week for twelve weeks. The three month delay was chosen to secure stability [20]. The physical training program consists of an individual consultation with the physiotherapist and an individually tailored training programme. A test of aerobic functioning, patients' experiences and usual activities are elements in planning an individual programme. Patients do both resistance and aerobic training, to gain muscle strength and endurance and to gain reduction in after load with a decrease in systemic resistance [30]. The training has either a supervised group format in-hospital or is done at home or in a local hospital rehabilitation setting. The patients use pulse watches while exercising, to ensure that the recommended intensity of the training programme is obtained, and to ensure that the ICD activation threshold is not reached. During the physical training the pulse is noted, at 4 specific times. The 
Table 1 Inspiration Guide for Nursing Consultations

\begin{tabular}{|c|c|c|c|c|c|c|c|c|}
\hline & 1 & 2 & 3 & 4 & 5 & 6 & 7 & 85 \\
\hline What happened since you were here last time? How have you been? & $\mathrm{x}$ & $x$ & $x$ & $x$ & $x$ & $\mathrm{x}$ & $\mathrm{x}$ & $x \times$ \\
\hline Discuss the events leading up to the ICD implant. Experiences before and during admission. & $\mathrm{x}$ & & & & & & & \\
\hline Address present thoughts and questions & $\mathrm{x}$ & $x$ & $x$ & $\mathrm{x}$ & $x$ & $x$ & $\mathrm{x}$ & 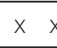 \\
\hline Were there any episodes from the ICD? & $x$ & $x$ & $x$ & $x$ & $x$ & $x$ & $x$ & $\times \quad \times$ \\
\hline $\begin{array}{l}\text { How did you having an ICD affect your life? Are there any activities you avoid? Are there any places you avoid? Are } \\
\text { there objects you avoid? }\end{array}$ & & $x$ & & & & & & \\
\hline Did you make an appointment with the physiotherapist/how is training going? & & & $x$ & $x$ & $x$ & $x$ & $x$ & $\times \quad x$ \\
\hline Discuss family, how do they tackle, changing patters in the family? & & & & $x$ & $x$ & $x$ & & \\
\hline Information, technical/recommendations. & $x$ & & & & $x$ & & & \\
\hline Shock (ad hoc)/phantom shock & & & $x$ & & & & & \\
\hline Changing view on the body? & & & & $x$ & & & & \\
\hline Driving & & $x$ & & & & & & \\
\hline Sexuality, is this affected? & & & & $x$ & & & & $x$ \\
\hline
\end{tabular}

patients exercise aerobically, at 50-80\% of their estimated maximum pulse, calculated by the Karvonen formula [31]. The target exercise heart rate is close to $80 \%$ of their maximum capacity. Patients are encouraged to exercise intensively, to obtain the maximum effect of the training, but not to fatigue themselves. Resistance training is done by $60-80 \%$ of one-repetition maximum (1-RM). The training pulse is allowed to rise to a maximum 10 - 15 beats below the ICD activation threshold [30]. To obtain cardiovascular adjustment, it is important to warm up and cool down, to minimize the risk of ischemia and arrhythmia [27,32]. The patients primarily exercise in an upright position, to reduce left ventricular filling pressure and minimize the risk of ischemia or heart failure ventricular arrhythmia [32].

Group training at the hospital The exercise training takes place in a supervised group with planned elements that are individually adjusted with respect to capacity, and risk of injuries.

One session consists of the following; $10 \mathrm{~min}$. warm up, 8 min. biking, $8 \mathrm{~min}$. walking/jogging/running, 8 min. individual aerobic endurance training e.g. step, stairway or running and resistance training of the major muscle groups. The session ends with $10 \mathrm{~min}$. cool down and relaxation. Two physiotherapists with 2-3 years of experience each ran the exercise training programme.

Home training Patients that cannot not attend exercise training at the hospital, are given an individual programme based on the above principles and instructed how to use a pulse watch with extended memory to monitor all training sessions. This is done in order to guide patients and to ensure adherence to instructions.

An overview of the intervention timeline and data collection is presented in Figure 2.

\section{Standard care}

Patients in the control group follow the standard care procedure, which is medical follow-up and an invitation to participate in a 2 hour group meeting, which includes information about the ICD and exchange of experiences among patients. In the standard care group no psychoeducational follow-up or exercise training are provided. A bias may occur if patients are offered cardiac rehabilitation at their local hospital. As a national law encourages rehabilitation for all cardiac patients, it is not possible to completely avoid participation in local initiatives. Patients are asked whether they had participated in such activities at the12 months follow-up.

\section{Outcomes}

Using questionnaires, interviews, exercise-tests, a 6-minute walk test (6-MWT), interrogation of the ICD and register-based follow-up, the effect and meaning of the programme are evaluated (Table 2). The pre-training exercise test is performed at 3 months and therefore not reported here.

Primary outcome measures: Due to the nature of rehabilitation, including both physical and psychological components, the two primary outcome measures are perceived health measured by the Short Form-36 [33,34] questionnaire and Peak VO2, measured by a standardized protocol according to guidelines [35]. The test is performed on bicycle ergometer with an initial workload of $12.5 \mathrm{~W}$ and increased $12.5 \mathrm{w}$ every minute until exhaustion or at 5 beats/min heart rate below ICD activation threshold. No gas analyses are conducted.

Secondary outcome measures: Physical capability is measured by an exercise test combined with the six minutes walk tests which have been proved to be effective measures of functional capacity in patients performing 


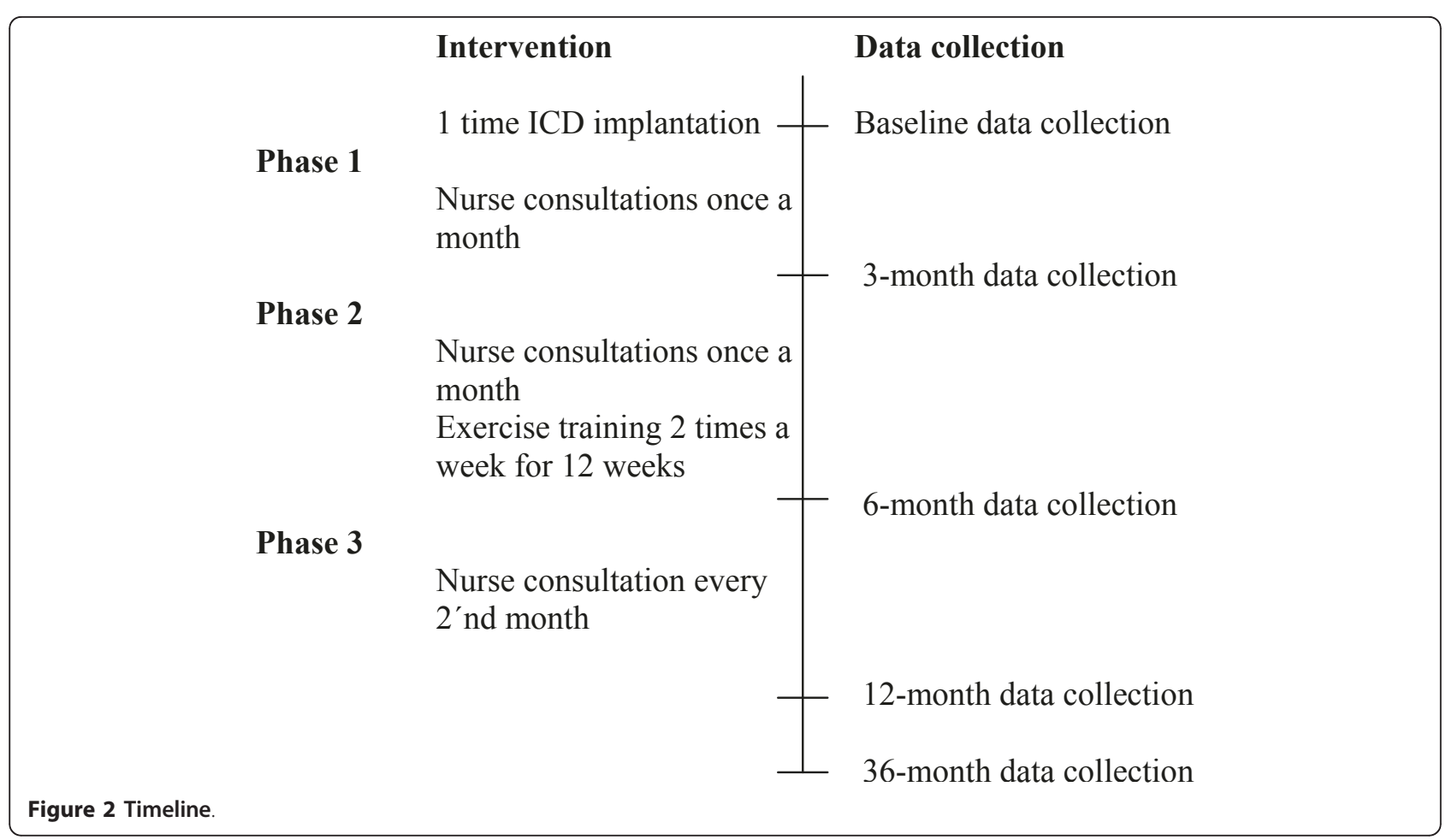

cardiac rehabilitation [30,36,37]. Further, exercise training data consist of the number of sessions, duration and heart rate.

Ventricular arrhythmia: 1. ICD-shock 2. Anti-tachycardia pacing is registered by interrogation of the ICD.

Questionnaires: Quality of life is measured by Quality of Life Index-Cardiac version (QLI-C) [38], knowledge of the ICD by Sudden Cardiac Death (SCD) knowledge assessment [20], ICD-adaptation using Implanted Devices Adjustment Scale (IDAS) [39], sexual problems

Table 2 Outcome Measures

\begin{tabular}{ll}
\hline Measurement & Time \\
\hline SF-36 & Baseline, 3-6-12 month \\
\hline IDAS & Baseline, 3-6-12 month \\
\hline Sex after ICD survey & Baseline, 3-6-12 month \\
\hline ICD and Avoidance Survey & 6 month \\
\hline SCA knowledge assessment & 6-12 month \\
\hline Exercise test, 6MWT & Baseline, 12 month \\
\hline ICD interrogation & 3-6 month \\
\hline Work & 3-6-12 month \\
\hline Rehabilitation elsewhere & 12 month \\
\hline Qualitative interview & 12 month \\
\hline Registry data & 12 month \\
\hline
\end{tabular}

SF-36 and exercise test are primary outcome measures. or dysfunction by the Sex After ICD Survey [40] and avoidance behaviour is measured by ICD and Avoidance Survey [40].

Ancillary questions developed for this study: amount of participation in rehabilitation outside the project, and work status/sick leave before and after ICD implantation.

Registry data: Registry data is collected regarding death, hospitalisation, emergency room visits, outpatient visits, medication and employment status. The national registries function very well with a small percentage of lost data and thus are well suited to measure effects, even in small patient populations. Data is extracted from the Danish National Patient Register, the Danish National Health Service Register, the Danish National Prescription Registry and the Danish National Causes of Death Register.

Demographic variables and diagnoses are collected from medical records.

The qualitative study:

The qualitative study seeks to answer the following questions in order to fulfil the purpose of the trial:

Thematic research questions:

- What are the experiences of participating in the COPE-ICD program?

- What is the meaning of participating in the program?

- Which components of the outpatient program are meaningful, and how are they meaningful? 
Ten patients (10\%) from the intervention group are interviewed at the end of intervention. Qualified interviewees are chosen (knowledgeable, articulate), representative in terms of stratification, gender and left ventricular ejection fraction (LVEF) and according to the reason for ICD implantation (primary/secondary prevention) to achieve maximum variation [41]. The analysis is inspired by Ricoeur's theory of interpretation and consists of three levels: naive reading, structured analysis and critical interpretation and discussion [42].

\section{Sample size}

\section{Physical capacity}

Based on current knowledge (1), we estimate a difference in V02max of $15 \%$ between the rehabilitation group and standard care group $(\mathrm{SD}=0.3)$. A total number of 128 patients are estimated for the trial (alfa $=5 \%$, beta $=20 \%)$. Health status outcome measure: Based on health status measures among a Danish population compared to patient with heart disease a baseline meanscore of the SF-36 general health $(\mathrm{GH})$ is estimated to be $60(\mathrm{SD}=22)$. The effect of rehabilitation is expected to be 10 absolute points. A total number of 154 patients are needed in the trial $(\mathrm{alfa}=5 \%$, beta $=20 \%)$. The study includes 196 patients, taking a drop-out rate of $20 \%$ into account. In the previous trials a drop-out rate around $20 \%$ was found, with no significant differences in baseline information on any study variable between groups and no difference in the number of dropouts in each group $[11,17,19,21,23]$.

\section{Blinding}

Because of the nature of rehabilitation, the interventions are open to the staff and the patients. A blinded investigator performs all physical tests, data collection and administration. Blinded outcome analyses are conducted.

\section{Statistical methods}

The statistical analyses of the effects of rehabilitation are conducted based on a predefined statistical protocol using SPSS 17.0 for Windows. The analysis will adopt an analytical approach on all available data, meaning that all data obtained are included in analyses, regardless of adherence to the study protocol. Only data from patients following through the program will be included in the analysis of the endpoints. Accordingly, there is no imputation of missing data. Questionnaire responses will be converted to numerical scores using standard methodologies. Continuous data are checked for normality of distribution, and log-transformed if required. The baseline characteristics will be presented by group to present similarities across treatment, but according to recommendations no significant testing will be performed [43]. The socio-demographic and clinical characteristics of individuals who drop out from the study will be compared with those who completed the study and drop-out characteristics between groups will be compared. The effectiveness of the intervention will be examined using blinded analysis of variance. The primary comparisons will be Two independent samples $\mathrm{T}$-test for the mean difference between two independent samples. Paired Ttests of equality of means will be used for within group analysis of difference over time. Further, univariable and multivariable regression analysis will also be used to investigate the effect of the intervention on the endpoints. The type of regression analysis will depend on the endpoint in question. Demographic, clinical and questionnaire data will be included in multivariable analysis in order to control for their potential confounding effects. The level of significance is set at $p<0.05$. Data will, for continues data, be shown as means \pm standard deviation or percentage. Categorical data will be shown as percent. Twelve month follow-up data and results obtained from Danish registries regarding hospitalisations are used for follow-up comparison. Due to the skewed distribution of length of hospital stay and repeated measurements of hospital admissions on patients these register-based tertiary outcomes will be analyzed using multivariate random-effect modelling with patients as random effects. Further analysis will be conducted using the Cox regression model including time to first event as outcome variable. At baseline 46\% $(n=91)$ of the population was employed. This is a rather small number of patients and sickness absence will be included as a measure when evaluating employment status. The direct costs of healthcare are calculated by a retrospective top-down method [44]. All other costs are extracted from relevant registers.

\section{Ethical considerations}

The study is approved by the regional Ethics Committee (j.nr. H-B-2007-014), National Agency for Data Security (j.nr. 2007-41-0932) and registered at ClinicalTrials.gov (ID: NCT00569478). Patients were asked to participate in the study after receiving oral and written information, and were given time to reflect on their participation in the study before giving written informed consent. All data are treated in confidence and patients are assured anonymity. The study follows the recommendations of the Declaration of Helsinki II [45].

\section{Safety}

No risks are anticipated during the psycho-educational consultations.

Studies have shown that it was safe for patients with ICDs to participate in physical training $[13,16,27]$. This intervention is not aimed at maximum performance, but is a recreational programme. A "cool down" period was 
incorporated in exercise and testing, which has previously resulted in 45,000 exercise tests without complications over a 10 year period [46].

\section{Participants recruitment and flow}

During the inclusion period October 2007-November 2009, 610 patients had ICD implantation at the hospital (Figure 3). Due to local policies patients were not asked to participate if they were eligible for or included in pharmaceutical trials. Not meeting the inclusion criteria was due to other somatic diseases $(n=49)$, psychiatric disease or cognitive dysfunction $(n=20)$ and language $(\mathrm{n}=11)$. A total of 196 patients were included.

\section{Baseline measures}

Most participants are men (79\%) and the mean age was 58 (SD 13.2), range 20-85. The mean LVEF is 32 (SD17.5) and most (46\%) are NYHA class 2 and $64 \%$ received the ICD for primary prevention (Table 3 ). The medication status at baseline is presented in Table 4 . The mean walk capacity measured by $6 \mathrm{MWT}$ is $417 \mathrm{~m}$., Table 5. The perception of health measured by SF-36 is 42.6 for physical component scale (PCS) and 47.1 for mental component scale (MCS), a higher score indicating better perception of health, scale range $0-100$ (Table 6). Quality of life score is 26.4 (Table 6), scale range from 0-36, a higher score indicating better quality of life. Baseline knowledge of the ICD score is 20 (Table 6), scale range 0-25.

\section{Discussion}

Demographic data and clinical variables are similar between the groups. The baseline characteristics are similar to other ICD rehabilitation populations regarding NYHA, LVEF, gender, type of device and indication $[20,21]$. The baseline measures of knowledge and skills needed to live with an ICD, SCA Knowledge score 20, are similar to the ICD rehabilitation population that

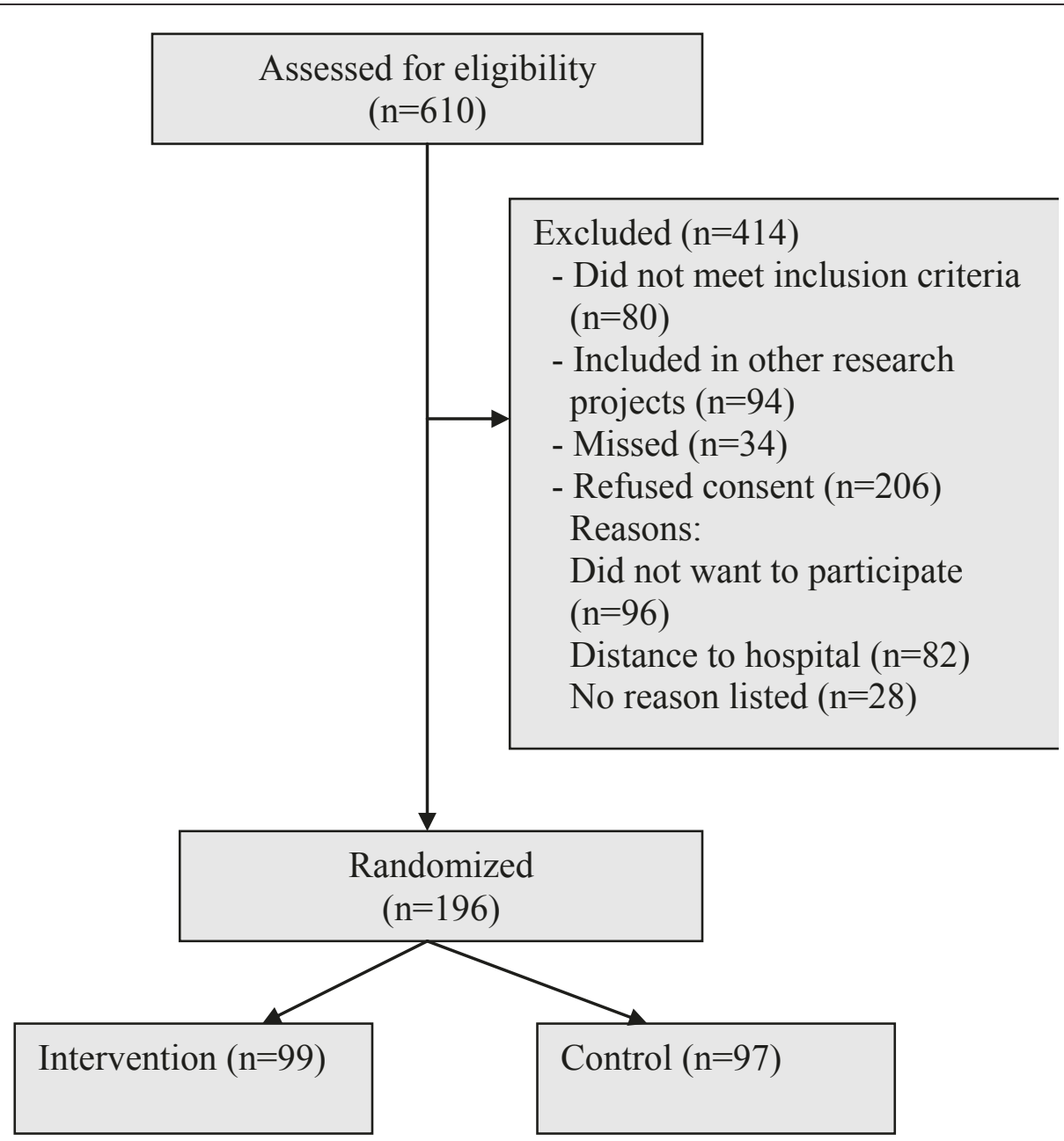

Figure 3 Flowchart of Patients Included in COPE-ICD. 
Table 3 Demographic and Physical Profile

\begin{tabular}{lll}
\hline & $\begin{array}{l}\text { Control } \\
\text { gr. } \boldsymbol{n}(\%)\end{array}$ & $\begin{array}{l}\text { Intervention } \\
\text { gr. } \mathbf{n}(\%)\end{array}$ \\
\hline Male gender & $76(78)$ & $79(80)$ \\
\hline Age (mean) & 58 & 58 \\
\hline Employed & $50(52)$ & $41(42)$ \\
\hline Primary prophylactic indication & $67(69)$ & $63(64)$ \\
\hline VF prior to ICD implantation & $20(20)$ & $21(21)$ \\
\hline LVEF (mean/SD) 73\% of tot pop $\leq 35$ & $32.7(18)$ & $32.2(17)$ \\
\hline NYHA I & $18(19)$ & $30(31)$ \\
\hline NYHA II & $44(46)$ & $42(43)$ \\
\hline NYHA III & $32(33)$ & $24(25)$ \\
\hline NYHA IV & $1(1)$ & $2(2)$ \\
\hline BMI $\geq 30$ & $19(20)$ & $24(24)$ \\
\hline Atial fibrillation & $21(22)$ & $27(27)$ \\
\hline CRT device & $9(9)$ & $14(14)$ \\
\hline History of IHD & $57(59)$ & $45(46)$ \\
\hline Previous MI & $33(34)$ & $20(21)$ \\
\hline Previous PCI & $29(30)$ & $28(29)$ \\
\hline Previous CABG & $21(22)$ & $14(15)$ \\
\hline History of HF & $73(75)$ & $76(78)$ \\
\hline Diabetes & $10(10)$ & $12(12)$ \\
\hline Hypertension & $23(24)$ & $18(18)$ \\
\hline COLD & $1(1)$ & $2(2)$ \\
\hline Other chronic disease & $24(25)$ & $27(28)$ \\
\hline CRT Cor & \\
\hline
\end{tabular}

CRT: Coronary resync. therapy. IHD: Ischemic heart disease. MI: Myocardial infarction. PCl: Percutaniuos catheter intervention. CABG: Coronary artery bypass graft. HF: Heart failure. COLD: Chronic Obstructive Lung Disease.

originally tested the questionnaire, score 21 [20]. The population is also similar to other ICD populations regarding quality of life, with very similar scores in all subscales $[47,48]$. Perceived health measured by SF-36 is also similar to other findings as to the mental and emotional health, but with somewhat higher scores in physical function and pain [48].

Testing 6-MWT showed that this population might have a higher physical capacity $(417 \mathrm{~m})$ than other ICD populations (328 m, $383 \mathrm{~m}$ ) [49,50], which can possibly be explained by a slightly higher LVEF and younger age.

Table 4 Baseline Medication

\begin{tabular}{lll}
\hline & Control gr. $\mathbf{n}(\%)$ & Intervention gr. $\mathbf{n}(\%)$ \\
\hline Betablockers & $83(86)$ & $76(76)$ \\
\hline Calcium antagonist & $6(6)$ & $18(18)$ \\
\hline Amiodarone & $8(8)$ & $11(11)$ \\
\hline ACE inhibitors & $67(69)$ & $69(69)$ \\
\hline Digoxin & $8(8)$ & $12(12)$ \\
\hline Prolonged nitrates & $7(7)$ & $4(4)$ \\
\hline Insulin & $4(4)$ & $5(5)$ \\
\hline
\end{tabular}

Table 56 MWT Baseline

\begin{tabular}{lll}
\hline & $\begin{array}{l}\text { Control gr. } \\
\text { score. }\end{array}$ & $\begin{array}{l}\text { Intervention gr. } \\
\text { score. }\end{array}$ \\
\hline Distance meter (SD) & $415(118)$ & $420(112)$ \\
\hline $\begin{array}{l}\text { *Shortness of breath Pre-test } \\
\text { (Cl) }\end{array}$ & $1.1(0.7-1.3)$ & $0.9(0.5-1.3)$ \\
\hline $\begin{array}{l}\text { *Shortness of breath Post-test } \\
\text { (Cl) }\end{array}$ & $3.2(2.6-3.8)$ & $2.8(2.2-3.4)$ \\
\hline *Exertion pre-test $(\mathrm{Cl})$ & $2.1(1.5-2.7)$ & $1.7(1.3-2.3)$ \\
\hline *Exertion post-test $(\mathrm{Cl})$ & $2.5(1.8-3.1)$ & $2.2(1.5-2.8)$ \\
\hline
\end{tabular}

*BORG CR 10 Scale.

Mean values and $95 \%$ confidence interval

This intervention is expensive from a rehabilitation perspective with 9 nurse consultations, 2 individual consultations with a physiotherapist and 2 weekly exercise training group sessions offered at the hospital. The planned economic analysis will reveal the cost-benefit ratio of this comprehensive rehabilitations programme. The set-up of this programme can be done in any cardiac rehabilitation setting after proper education of nurses and physiotherapists.

Study limitations include the fact that that selection bias may exist due to patients not being included if they were already included in a pharmaceutical trial. The control group might be contaminated by the information given during the project inclusion, suggesting that psycho-educational assistance and exercise training might be beneficial after ICD implantation. This information could lead to control patients seeking rehabilitation elsewhere if they believe it is effective. There is an

Table 6 SF-36, QoL -cardiac version, SCA knowledge.

\begin{tabular}{lll}
\hline & $\begin{array}{l}\text { Control gr. score, } \\
\text { mean (SD) }\end{array}$ & $\begin{array}{l}\text { Intervention gr. score, } \\
\text { mean (SD) }\end{array}$ \\
\hline PCS & $43.4(8.5)$ & $41.9(10.2)$ \\
\hline MCS & $46.7(11.5)$ & $47.4(10.4)$ \\
\hline Physical Function & $69.8(22.6)$ & $69.7(21.4)$ \\
\hline Role Physical & $39.1(42.3)$ & $36.6(42.7)$ \\
\hline Bodily Pain & $71.2(27.7)$ & $71.2(27.1)$ \\
\hline General Health & $59.5(19.2)$ & $58.7(21.9)$ \\
Perceptions & & \\
\hline Vitality & $53.5(22.8)$ & $55.6(22.9)$ \\
\hline Social Functioning & $77.7(24.9)$ & $76.8(25.9)$ \\
\hline Role Emotional & $56.3(39.1)$ & $51.0(43.7)$ \\
\hline Mental Health & $69.3(21.3)$ & $72.5(20.6)$ \\
\hline QLI & $26.5(5.3)$ & $26.3(6.3)$ \\
\hline HFSUBa & $23.4(5.7)$ & $23.5(6.9)$ \\
\hline SOCSUBb & $29.9(6.4)$ & $29.6(7.1)$ \\
\hline PSPSUBC & $26.8(9.4)$ & $26.0(8.2)$ \\
\hline FAMSUBd & $30.0(5.1)$ & $29.6(8.7)$ \\
\hline SCA knowledge & $20.1(3.1)$ & $20(3.7)$ \\
\hline
\end{tabular}


expected drop-out rate at $20 \%$ which could influence the validity. Any difference between patients completing the intervention and those not completing (drop-outs) will be carefully discussed in evaluating the intervention, results and the suitability for implementation. The trial is designed with multiple statistical comparisons so results will be interpreted with caution.

In conclusion, whether a comprehensive rehabilitation programme improves quality of life and physical function have so far not been tested in larger prospective randomized controlled trials. The COPE-ICD trial is designed to test this hypothesis. The baseline data indicate a study population with heart failure, representative for ICD patients in general, similar to previous studies. This is the largest randomized trial in ICD patients to date, and will help determine the value of a comprehensive rehabilitation programme. Furthermore, the study's results will undoubtedly impact on rehabilitation practice and the control group in this study will provide valuable information on the current natural history of contemporary ICD patients. The first results will be published in 2011.

\section{Abbreviations}

ICD: Implantable cardioverter defibrillator; COPE-ICD: Copenhagen Outpatient ProgrammE; METS: metabolic equivalent.

\section{Acknowledgements}

This trial is funded by Novo Nordisk Foundation, Oticon Foundation, The Danish Heart Foundation, AP Møller and Chastine Mc-Kinney Møller Foundation, Helsefonden, Tryg Foundation, Augustinus Foundation, DACRA, Krista and Viggo Petersens Foundation, King Christian the 10'th Foundation and Copenhagen University Hospital, Rigshospitalet.

\section{Author details}

${ }^{1}$ Rigshospitalet, The Heart Center, University of Copenhagen, Copenhagen, Denmark. ${ }^{2}$ University of Aarhus, Institute of Public Health, Aarhus, Denmark. ${ }^{3}$ University of Copenhagen, Institute of Surgery and Medicine, Copenhagen, Denmark. ${ }^{4}$ The Danish National Research Foundation Center for Cardiac Arrhythmia (DARC), University of Copenhagen, Copenhagen, Denmark. ${ }^{5}$ University of Southern Denmark, Institute of Public Health, Denmark.

University of Southern Denmark, Clinical Institute, Denmark.

\section{Authors' contributions}

SKB in collaboration with JHS, ADZ, PUP, BDP designed the study. SKB in collaboration with $\mathrm{LSH}, \mathrm{PP}, \mathrm{MBH}, \mathrm{RHN}$ provided the basis for the intervention. SKB drafted the manuscript. All revised the manuscript critically. All have given their final approval of the version to be published.

\section{Competing interests}

The authors declare that they have no competing interests.

Received: 9 June 2011 Accepted: 17 June 2011 Published: 17 June 2011

\section{References}

1. Zipes DP, Camm AJ, Borggrefe M, Buxton AE, Chaitman B, Fromer M, Gregoratos G, Klein G, Moss AJ, Myerburg RJ, Priori SG, Quinones MA, Roden DM, Silka MJ, Tracy C, Priori SG, Blanc JJ, Budaj A, Camm AJ, Dean V, Deckers JW, Despres C, Dickstein K, Lekakis J, McGregor K, Metra M, Morais J, Osterspey A, Tamargo JL, Zamorano JL, Smith SC Jr, Jacobs AK, Adams CD, Antman EM, Anderson $J$ L, Hunt SA, Halperin $J$ L, Nishimura R, Ornato JP, Page RL, Riegel B, American College of Cardiology American Heart Association Task Force European Society of Cardiology Committee for
Practice Guidelines European Heart Rhythm Association Heart Rhythm Society: ACC/AHA/ESC 2006 guidelines for management of patients with ventricular arrhythmias and the prevention of sudden cardiac death: a report of the American College of Cardiology/American Heart Association Task Force and the European Society of Cardiology Committee for Practice Guidelines (Writing Committee to Develop guidelines for management of patients with ventricular arrhythmias and the prevention of sudden cardiac death) developed in collaboration with the European Heart Rhythm Association and the Heart Rhythm Society. Europace 2006, 8:746-837.

2. Al-Khatib SM, Sanders GD, Carlson M, Cicic A, Curtis A, Fonarow GC, Groeneveld PW, Hayes D, Heidenreich P, Mark D, Peterson E, Prystowsky EN, Sager P, Salive ME, Thomas K, Yancy CW, Zareba W, Zipes D: Preventing tomorrow's sudden cardiac death today: dissemination of effective therapies for sudden cardiac death prevention. Am Heart J 2008, 156:613-622.

3. Sheldon R, Connolly S, Krahn A, Roberts R, Gent M, Gardner M: Identification of patients most likely to benefit from implantable cardioverter-defibrillator therapy: the Canadian Implantable Defibrillator Study. Circulation 2000, 101:1660-1664.

4. Thomas SA, Friedmann E, Kelley FJ: Living with an implantable cardioverter-defibrillator: a review of the current literature related to psychosocial factors. AACN Clin Issues 2001, 12:156-163.

5. Sears SF Jr, Todaro JF, Lewis TS, Sotile W, Conti JB: Examining the psychosocial impact of implantable cardioverter defibrillators: a literature review. Clin Cardiol 1999, 22:481-489.

6. Lemon J, Edelman S, Kirkness A: Avoidance behaviors in patients with implantable cardioverter defibrillators. Heart Lung 2004, 33:176-182.

7. Sears SF, Lewis TS, Kuhl EA, Conti JB: Predictors of quality of life in patients with implantable cardioverter defibrillators. Psychosomatics 2005, 46:451-457.

8. Godemann F, Butter C, Lampe F, Linden M, Werner S, Behrens S: Determinants of the quality of life (QoL) in patients with an implantable cardioverter/defibrillator (ICD). Qual Life Res 2004, 13:411-416.

9. Steinberg JS, Arshad A, Kowalski M, Kukar A, Suma V, Vloka M, Ehlert F, Herweg B, Donnelly J, Philip J, Reed G, Rozanski A: Increased incidence of life-threatening ventricular arrhythmias in implantable defibrillator patients after the World Trade Center attack. J Am Coll Cardiol 2004, 44:1261-1264

10. Shedd OL, Sears SF Jr, Harvill JL, Arshad A, Conti JB, Steinberg JS, Curtis AB: The World Trade Center attack: increased frequency of defibrillator shocks for ventricular arrhythmias in patients living remotely from New York City. J Am Coll Cardiol 2004, 44:1265-1267.

11. Kohn CS, Petrucci RJ, Baessler C, Soto DM, Movsowitz C: The effect of psychological intervention on patients' long-term adjustment to the ICD: a prospective study. Pacing Clin Electrophysiol 2000, 23:450-456.

12. Ladwig KH, Baumert J, Marten-Mittag B, Kolb C, Zrenner B, Schmitt C: Posttraumatic stress symptoms and predicted mortality in patients with implantable cardioverter-defibrillators: results from the prospective living with an implanted cardioverter-defibrillator study. Arch Gen Psychiatry 2008, 65:1324-1330.

13. Davids JS, McPherson CA, Earley C, Batsford WP, Lampert R: Benefits of cardiac rehabilitation in patients with implantable cardioverterdefibrillators: a patient survey. Arch Phys Med Rehabil 2005, 86:1924-1928.

14. Dougherty CM, Glenny R, Kudenchuk PJ: Aerobic exercise improves fitness and heart rate variability after an implantable cardioverter defibrillator. J Cardiopulm Rehabil Prev 2008, 28:307-311.

15. Belardinelli R, Capestro F, Misiani A, Scipione P, Georgiou D: Moderate exercise training improves functional capacity, quality of life, and endothelium-dependent vasodilation in chronic heart failure patients with implantable cardioverter defibrillators and cardiac resynchronization therapy. Eur J Cardiovasc Prev Rehabil 2006, 13:818-825.

16. Vanhees L, Kornaat M, Defoor J, Aufdemkampe G, Schepers D, Stevens A, Van Exel H, Van Den Beld J, Heidbuchel H, Fagard R: Effect of exercise training in patients with an implantable cardioverter defibrillator. Eur Heart J 2004, 25:1120-1126.

17. Vanhees L, Schepers D, Heidbuchel H, Defoor J, Fagard R: Exercise performance and training in patients with implantable cardioverterdefibrillators and coronary heart disease. Am J Cardiol 2001, 87:712-715.

18. Fan S, Lyon CE, Savage PD, Ozonoff A, Ades PA, Balady GJ: Outcomes and adverse events among patients with implantable cardiac defibrillators in 
cardiac rehabilitation: a case-controlled study. J Cardiopulm Rehabil Prev 2009, 29:40-43.

19. Crossmann A, Schulz SM, Kuhlkamp V, Ritter O, Neuser H, Schumacher B, Bauer W, Pauli P: A randomized controlled trial of secondary prevention of anxiety and distress in a German sample of patients with an implantable cardioverter defibrillator. Psychosom Med 2010, 72:434-441.

20. Dougherty CM, Lewis FM, Thompson EA, Baer JD, Kim W: Short-term efficacy of a telephone intervention by expert nurses after an implantable cardioverter defibrillator. Pacing Clin Electrophysiol 2004, 27:1594-1602.

21. Dunbar SB, Langberg JJ, Reilly CM, Viswanathan B, McCarty F, Culler SD, O'Brien MC, Weintraub WS: Effect of a psychoeducational intervention on depression, anxiety, and health resource use in implantable cardioverter defibrillator patients. Pacing Clin Electrophysiol 2009, 32:1259-1271.

22. Kuhl EA, Sears SF, Vazquez LD, Conti JB: Patient-assisted computerized education for recipients of implantable cardioverter defibrillators: a randomized controlled trial of the PACER program. J Cardiovasc Nurs 2009, 24:225-231.

23. Lewin RJ, Coulton S, Frizelle DJ, Kaye G, Cox H: A brief cognitive behavioural preimplantation and rehabilitation programme for patients receiving an implantable cardioverter-defibrillator improves physical health and reduces psychological morbidity and unplanned readmissions. Heart 2009, 95:63-69.

24. Dickerson SS, WU YW, Kennedy MC: A CNS-facilitated ICD support group: a clinical project evaluation. Clin Nurse Spec 2006, 20:146-153.

25. Dunbar SB, Kimble LP, Jenkins LS, Hawthorne M, Dudley W, Slemmons M, Langberg JJ: Association of mood disturbance and arrhythmia events in patients after cardioverter defibrillator implantation. Depress Anxiety 1999, 9:163-168.

26. Frizelle DJ, Lewin RJ, Kaye G, Hargreaves C, Hasney K, Beaumont N, MonizCook E: Cognitive-behavioural rehabilitation programme for patients with an implanted cardioverter defibrillator: a pilot study. Br J Health Psychol 2004, 9:381-392.

27. Fitchet A, Doherty PJ, Bundy C, Bell W, Fitzpatrick AP, Garratt CJ: Comprehensive cardiac rehabilitation programme for implantable cardioverter-defibrillator patients: a randomised controlled trial. Heart 2003, 89:155-160.

28. Creswell JW, Plano Clark VL: Designing and conducting mixed methods research. Thousand Oaks, Calif: SAGE Publications; 2007.

29. Parse RR: The human becoming school of thought: a perspective for nurses and other health professionals. Thousand Oaks, Calif:: Sage; 1998.

30. Perk J, Mathes P, Gohlke H, Monpére C, Hellemans I, McGee H, Sellier P, Saner H, eds: Cardiovascular Prevention and Rehabilitation. London: Springer-Verlang; 2007.

31. Tabet JY, Meurin P, Ben Driss A, Thabut G, Weber H, Renaud N, Odjinkem N, Solal AC: Determination of exercise training heart rate in patients on beta-blockers after myocardial infarction. Eur J Cardiovasc Prev Rehabil 2006, 13:538-543.

32. Lampman RM, Knight BP: Prescribing exercise training for patients with defibrillators. Am J Phys Med Rehabil 2000, 79:292-297.

33. Ware JE Jr, Sherbourne CD: The MOS 36 -item short-form health survey (SF-36). I. Conceptual framework and item selection. Med Care 1992, 30:473-483.

34. McHorney CA, Ware JE Jr, Raczek AE: The MOS 36-Item Short-Form Health Survey (SF-36): II. Psychometric and clinical tests of validity in measuring physical and mental health constructs. Med Care 1993, 31:247-263.

35. Gibbons RJ, Balady GJ, Bricker JT, Chaitman BR, Fletcher GF, Froelicher VF, Mark DB, McCallister BD, Mooss AN, O'Reilly MG, Winters WL, Gibbons RJ, Antman EM, Alpert JS, Faxon DP, Fuster V, Gregoratos G, Hiratzka LF, Jacobs AK, Russell RO, Smith SC: American College of Cardiology/ American Heart Association Task Force on Practice Guidelines. Committee to Update the 1997 Exercise Testing Guidelines. ACC/AHA 2002 guideline update for exercise testing: summary article. J Am Coll Cardiol 2002, 40:1531-1540, A report of the American College of Cardiology/American Heart Association Task Force on Practice Guidelines (Committee to Update the 1997 Exercise Testing Guidelines).

36. ATS Committee on Proficiency Standards for Clinical Pulmonary Function Laboratories: ATS statement: guidelines for the six-minute walk test. Am J Respir Crit Care Med 2002, 166:111-117.
37. Wright DJ, Khan KM, Gossage EM, Saltissi S: Assessment of a low-intensity cardiac rehabilitation programme using the six-minute walk test. Clin Rehabil 2001, 15:119-124.

38. Ferrans CE, Powers MJ: Quality of life index: development and psychometric properties. ANS Adv Nurs Sci 1985, 8:15-24

39. Beery TA, Baas LS, Matthews $H$, Burroughs J, Henthorn R: Development of the implanted devices adjustment scale. Dimens Crit Care Nurs 2005, 24:242-248.

40. Steinke EE, Gill-Hopple K, Valdez D, Wooster M: Sexual concerns and educational needs after an implantable cardioverter defibrillator. Heart Lung 2005, 34:299-308.

41. Polit DFHBP: Essentials of Nursing Research, Methods, Appraisal, and Utilization. Lippincott; 1997.

42. Ricoeur P: Time and narrative. The University of Chicago Press; 1988.

43. Assmann SF, Pocock SJ, Enos LE, Kasten LE: Subgroup analysis and other (mis)uses of baseline data in clinical trials. Lancet 2000, 355:1064-1069.

44. Kruse M, Hochstrasser S, Zwisler AD, Kjellberg J: Comprehensive cardiac rehabilitation: a cost assessment based on a randomized clinical trial. Int J Technol Assess Health Care 2006, 22:478-483.

45. World Medical Association Declaration of Helsinki: ethical principles for medical research involving human subjects. JAMA 2000, 284:3043-3045.

46. Gibbons L, Blair SN, Kohl HW, Cooper K: The safety of maximal exercise testing. Circulation 1989, 80:846-852.

47. Steinberg JS, Joshi S, Schron EB, Powell J, Hallstrom A, McBurnie M, AVID Investigators: Psychosocial status predicts mortality in patients with lifethreatening ventricular arrhythmias. Heart Rhythm 2008, 5:361-365.

48. Kao CW, Friedmann E, Thomas SA: Quality of life predicts one-year survival in patients with implantable cardioverter defibrillators. Qual Life Res 2010, 19:307-315.

49. Kim JS, Pressler SJ, Welch JL, Damush T, Sloan RS, Wu J, Groh WJ: Physical function of patients with implantable cardioverter-defibrillators. J Cardiovasc Nurs 2009, 24:398-409.

50. Abraham WT, Young JB, Leon AR, Adler S, Bank AJ, Hall SA, Lieberman R, Liem LB, O'Connell JB, Schroeder JS, Wheelan KR, Multicenter InSync ICD II Study Group: Effects of cardiac resynchronization on disease progression in patients with left ventricular systolic dysfunction, an indication for an implantable cardioverter-defibrillator, and mildly symptomatic chronic heart failure. Circulation 2004, 110:2864-2868.

\section{Pre-publication history}

The pre-publication history for this paper can be accessed here: http://www.biomedcentral.com/1471-2261/11/33/prepub

doi:10.1186/1471-2261-11-33

Cite this article as: Berg et al: COPE-ICD: A randomised clinical trial studying the effects and meaning of a comprehensive rehabilitation programme for ICD recipients -design, intervention and population. BMC Cardiovascular Disorders 2011 11:33.

\section{Submit your next manuscript to BioMed Central and take full advantage of:}

- Convenient online submission

- Thorough peer review

- No space constraints or color figure charges

- Immediate publication on acceptance

- Inclusion in PubMed, CAS, Scopus and Google Scholar

- Research which is freely available for redistribution

Submit your manuscript at www.biomedcentral.com/submit
C Biomed Central 